\title{
KEMAMPUAN KOMUNIKASI MATEMATIS SISWA DITINJAU DARI GAYA BELAJAR
}

\author{
Muhammad Riyadi ${ }^{1}$, Heni Pujiastuti ${ }^{2}$ \\ Universitas Sultan Ageng Tirtayasa ${ }^{1,2}$ \\ jamesriyadi69@gmail.com ${ }^{1}$
}

\begin{abstract}
ABSTRAK
Tujuan penelitian ini adalah untuk mengetahui kemampuan komunikasi matematis siswa ditinjau dari gaya belajarnya. Metode penelitian yang digunakan ialah metode penelitian deskriptif. Data dikumpulkan melalui tes dan observasi. Subjek penelitian ini sebanyak 30 orang siswa dari SMK Kesehatan Husada Pratama, dengan masing-masing gaya belajar terdapat 10 subjek. Hasil penelitian menunjukkan bahwa kemampuan komunikasi matematis siswa dengan gaya belajar visual berada pada kategori kemampuan rendah, kemampuan komunikasi matematis siswa dengan gaya belajar auditori berada pada kategori kemampuan sedang, dan kemampuan komunikasi matematis siswa dengan gaya belajar kinestetik berada pada kategori kemampuan sedang. Pada hasil juga menunjukkan bahwa rerata total skor siswa dengan gaya belajar kinestetik lebih baik 1,9 dari siswa dengan gaya belajar auditori, dan lebih baik 4,3 dari siswa dengan gaya belajar visual. Hal ini menunjukkan bahwa kemampuan komunikasi matematis siswa SMK Kesehatan Husada Pratama berada pada kategori sedang, dan gaya belajar kinestetik lebih baik daripada gaya belajar visual ataupun auditori.
\end{abstract}

Kata kunci : kemampuan komunikasi matematis, gaya belajar

\begin{abstract}
The purpose of this study was to determine students' mathematical communication skills in terms of their learning styles. The research method used is descriptive. Data were collected through tests and observations. The subjects of this study were 30 students from SMK Kesehatan Husada Pratama, with 10 subjects for each learning style. The results showed that students mathematical communication skills with visual learning styles were in the low ability category, students' mathematical communication skills with auditory learning styles were in the moderate ability category, and students mathematical communication skills with kinesthetic learning styles were in the medium ability category. The results also show that the mean total score of students with kinesthetic learning styles is 1.9 better than students with auditory learning styles, and 4.3 better than students with visual learning styles. This shows that the mathematical communication skills of the students of SMK Kesehatan Husada Pratama are in the medium category, and the kinesthetic learning styles are better than visual or auditory learning styles.
\end{abstract}

Keywords : mathematical communication skills, learning styles 


\section{PENDAHULUAN}

Pada hakikatnya pendidikan mempunyai peran yang penting dan juga cukup sakral guna mengembangkan kemampuan, keilmuan dan potensi dalam kehidupan sehari-hari. Pendidikan dapat dikatakan sebagai suatu proses transfer nilai budaya dari generasi yang satu kepada generasi berikutnya yang telah diatur sedemikian rupa untuk menuju ke arah yang lebih baik dengan berbagai harapan kepada generasi ke depannya (Nasution, 2016).

Pendidikan memberikan jalan bagi terwujudnya keberhasilan dan kemajuan. Upaya untuk mencapai sesuatu yang lebih baik akan dapat diwujudkan melalui pendidikan yang terorganisir baik secara formal maupun non formal. Dalam penerapan pendidikan ini, diberikan pembelajaran ilmu-ilmu yang sangat berhubungan dengan kebutuhan hidup sehari-hari, khususnya ilmu-ilmu yang utama dan mendasar seperti bahasa dan matematika.

Matematika merupakan suatu ilmu yang universal yang mendasari perkembangan teknologi modern baik yang sudah ada sampai hari ini ataupun ke depan nantinya, matematika memiliki peranan penting dalam mengembangkan ketajaman berpikir manusia.

Perkembangan zaman yang semakin pesat pada bidang teknologi informasi dan komunikasi saat ini dilandasi oleh perkembangan pada bidang keilmuan matematika yang semakin maju, oleh karena itu untuk menguasai pemanfaatan teknologi informasi dan komunikasi di masa depan diperlukan penguasaan pada bidang matematika yang kuat sejak dini dan terus-menerus diberikan pembaharuan pada pembelajaran matematika (Romli, 2010; Tandililing, 2011). Menyadari pentingnya perihal penguasaan matematika, maka mata pelajaran matematika menjadi mata pelajaran yang wajib bagi siswa pada pendidikan dasar dan menengah.

Pembelajaran matematika adalah sebuah proses atau kegiatan belajar-mengajar yang di dalamnya mempelajari ilmu matematika guna memperoleh sebuah pengetahuan, keterampilan dan kemanfaatan yang optimal baik itu untuk diri sendiri maupun untuk orang lain dalam kehidupan nyata sehari hari. Kegiatan yang paling penting dalam pembelajaran matematika adalah menyelesaikan suatu permasalahan secara matematis, khususnya masalah yang nantinya akan ditemui baik di dalam sekolah maupun dalam proses kehidupan sehari hari (Supriadi dan Damayanti, 2016).

Pembelajaran matematika di sekolah pada hakikatnya memerlukan standar pembelajaran yang berfungsi untuk menghasilkan siswa yang memiliki berbagai kemampuan, mulai dari keterampilan dasar, kemampuan berpikir, penalaran matematis, dan pengetahuan yang mampu bermanfaat untuk khalayak banyak (Putri, 2011). Merujuk dari hal itu salah satu dari standar proses pembelajaran adalah sebuah komunikasi. Secara umum dapat dipahami bahwa komunikasi adalah bentuk interaksi penyampaian suatu informasi dari orang yang satu kepada orang yang lainnya. Komunikasi matematik merupakan kekuatan sentral dalam merumuskan konsep dan strategi, juga sebagai modal penyelesaian dalam eksplorasi dan investigasi, serta sebagai wadah untuk memperoleh informasi, berbagi informasi serta untuk mempertajam ide atau gagasan (Greenes and Schulman, 1996:168). Komunikasi matematis diperlukan oleh seluruh manusia atau khalayak banyak untuk mengkomunikasikan suatu gagasan atau penyelesaian masalah matematika, baik secara lisan, tulisan, ataupun visual, dan juga baik dalam pembelajaran matematika 
maupun di luar pembelajaran matematika (Prayitno, dkk, 2013; Wulandari, Suarsana, dan Pujawan, 2018).

Kemampuan komunikasi matematis yang sering muncul dalam suatu pembelajaran matematika (Taufiq, 2014) meliputi: (1) merefleksikan benda-benda nyata, gambar, dan diagram ke dalam bentuk-bentuk, ide, ataupun gagasan gagasan matematika; (2) membuat suatu gambaran situasi atau persoalan baik dengan metode lisan, tulisan, grafik dan aljabar; (3) menggunakan bahasa ataupun simbol matematika dalam menyatakan peristiwa sehari hari; (4) mendengarkan, berdiskusi atau berdialog, dan menulis tentang matematika; (5) membaca dengan menggunakan pemahaman suatu presentasi matematika tertulis; (6) membuat konjektur atau dugaan, menyusun argumen beserta gagasan, merumuskan definisi, dan generalisasi; (7) menjelaskan dan membuat pertanyaan tentang matematika. Sedangkan menurut Nari (2015) ada beberapa indikator kemampuan komunikasi matematis diantaranya, yaitu: (1) kemampuan dalam menghubungkan benda nyata, gambar, dan diagram ke dalam ide ataupun gagasan gagasan matematika; (2) kemampuan dalam menjelaskan ide, situasi, dan relasi matematika dalam bentuk tulisan; (3) kemampuan dalam menyatakan suatu peristiwa atau ide dalam bahasa atau simbol matematika.

Melalui kemampuan komunikasi matematis diharapkan siswa-siswa mampu menyatakan, menjelaskan, menggambarkan, dan juga mendengar sehingga membawa siswa pada pemahaman yang lebih mendalam tentang matematika, sebab komunikasi sangat berkontribusi dalam pencarian atau pengumpulan suatu keterangan, data, dan fakta dalam melakukan suatu proses dan juga pengaplikasian matematika (Lanani, 2013). Guna mengembangkan suatu kemampuan dalam berkomunikasi, orang tersebut juga dapat menyampaikannya dengan berbagai bahasa salah satunya adalah bahasa matematis (Syahri, 2017). Aspek-aspek komunikasi matematis adalah kemampuan peserta didik dalam menuliskan pernyataan, alasan, atau penjelasan, dan menggunakan istilah istilah, notasi, tabel, diagram, grafik, gambar, ilustrasi, model matematika atau rumus (Widjajanti, 2013). Untuk mencapai itu semua, ada beberapa hal yang harus diperhatikan lebih mendalam, salah satunya adalah gaya belajar daripada siswa tersebut yang nantinya akan mempermudah dan membantu siswa tersebut.

Gaya belajar adalah suatu cara seseorang dalam menerima, menyerap, dan memproses suatu informasi yang didapat, gaya belajar dibagi menjadi tiga jenis yaitu gaya belajar visual, auditorial, dan kinestetik (De Porter dan Hernacki, 2015). Siswa yang memiliki gaya belajar visual cenderung belajar dengan menitikberatkan pada sisi penglihatannya, siswa yang memiliki gaya belajar auditorial cenderung dengan mengandalkan sisi pendengarannya, sedangkan siswa yang memiliki gaya belajar kinestetik cenderung belajar dengan mempraktekkan secara langsung (Prinansa, 2017). Gaya belajar mampu memberikan suatu peran penting dalam suatu proses pembelajaran. Pemahaman terhadap karakteristik siswa pada setiap dimensi tidak hanya akan meningkatkan pengajaran saja, tetapi peningkatan proses pembelajaran secara keseluruhan (Mousa, 2014).

Gaya belajar mampu untuk menjadi jawaban atas segala pertanyaan tentang rendahnya komunikasi matematis yang ada, sebab dengan gaya belajar yang disenangi siswa, mereka mampu untuk lebih cepat dalam menyerap materi yang diberikan oleh pendidik. Dalam hal tersebut konteks gaya belajar menjadi sangat penting karena mampu untuk lebih meningkatkan dan mengembangkan pembelajaran yang hadir dimanapun itu ataupun untuk meningkatkan kemampuan 
siswa baik kemampuan komunikasi maupun kemampuan lainnya. Hal ini juga menjadi salah satu alternatif dalam mengatasi pembelajaran di Indonesia yang masih saja monoton, maka dari itu tujuan dari penelitian adalah untuk mengetahui dan mendeskripsikan kemampuan komunikasi matematis siswa ditinjau dari gaya belajar.

\section{METODE}

Penelitian ini merupakan penelitian deskriptif untuk menganalisis kemampuan komunikasi matematis siswa Sekolah Menengah Kejuruan (SMK) Kesehatan Husada Pratama Kota Serang dalam pembelajaran matematika yang ditinjau dari gaya belajar siswa. Penelitian ini dilakukan pada bulan Maret sampai April 2020 atau pada semester genap tahun pelajaran 2019/2020 di SMK Kesehatan Husada Pratama Kota Serang. Subjek dalam penelitian ini yaitu siswa SMK Kesehatan Husada Pratama Kota Serang, sebanyak 30 orang, dimana masing masing gaya belajar terdapat 10 subjek.

Metode pengumpulan data yang digunakan adalah tes dan observasi. Kemampuan komunikasi matematis siswa ditinjau dari gaya belajar diukur dengan tes uraian yang terdiri dari 5 soal, dimana masing masing soal bernilai sama yaitu 20. Penyusunan tes uraian yang digunakan diawali dengan membuat suatu kisi-kisi soal yang berdasarkan indikator kemampuan komunikasi matematis. Sedangkan observasi terhadap hasil tes siswa dilakukan untuk melihat bagaimana jawaban siswa dalam memenuhi kelengkapan kemampuan komunikasi matematisnya. Observasi hanya dilakukan pada 3 orang.

Instrumen tes yang digunakan berbentuk tes uraian yang memuat indikator kemampuan komunikasi matematis, yaitu : (1) kemampuan mengkomunikasikan situasi berbentuk soal cerita, (2) kemampuan menghubungkan dan menyatakan situasi yang berbentuk soal cerita ke dalam model matematika, (3) kemampuan memberikan penjelasan pada penjabaran proses atau penyusunan hasil jawaban. Setelah melalui tes, kemampuan komunikasi matematis siswa dibagi dalam 3 kategori, yaitu :

Tabel 1. Pembagian kategori kemampuan komunikasi berdasarkan rentang nilai

\begin{tabular}{cc}
\hline Rentang nilai & Kategori kemampuan \\
\hline $\mathrm{x}<70$ & Rendah \\
$70 \leq \mathrm{x}<85$ & Sedang \\
$85 \leq \mathrm{x} \leq 100$ & Tinggi \\
\hline
\end{tabular}




\section{HASIL DAN PEMBAHASAN}

Berdasarkan hasil penelitian, diperoleh data hasil tes kemampuan komunikasi matematis ditinjau dari gaya belajar siswa sebagai berikut.

Tabel 2. Data hasil penelitian dengan gaya belajar visual

\begin{tabular}{|c|c|c|c|c|c|c|c|}
\hline \multirow{2}{*}{ No. } & \multicolumn{5}{|c|}{ Skor Soal } & \multirow{2}{*}{ Total Skor } & \multirow{2}{*}{ Skor Maksimal } \\
\hline & 1 & 2 & 3 & 4 & 5 & & \\
\hline 1 & 0 & 0 & 20 & 15 & 17 & 52 & 100 \\
\hline 2 & 10 & 10 & 7 & 7 & 20 & 54 & 100 \\
\hline 3 & 10 & 20 & 7 & 17 & 7 & 61 & 100 \\
\hline 4 & 3 & 17 & 20 & 12 & 17 & 69 & 100 \\
\hline 5 & 17 & 17 & 14 & 17 & 4 & 69 & 100 \\
\hline 6 & 15 & 15 & 17 & 15 & 10 & 72 & 100 \\
\hline 7 & 15 & 13 & 18 & 15 & 12 & 73 & 100 \\
\hline 8 & 20 & 14 & 20 & 14 & 7 & 75 & 100 \\
\hline 9 & 13 & 20 & 20 & 17 & 10 & 80 & 100 \\
\hline 10 & 20 & 20 & 20 & 17 & 10 & 87 & 100 \\
\hline
\end{tabular}

Dari data hasil penelitian dengan gaya belajar visual didapat beberapa skor dari 10 siswa yang merupakan subjek dari gaya belajar visual yaitu: 52, 54, 61, 69, 69, $72,73,75,80,87$.

Tabel 3. Data hasil penelitian dengan gaya belajar auditori

\begin{tabular}{|c|c|c|c|c|c|c|c|}
\hline \multirow{2}{*}{ No. } & \multicolumn{5}{|c|}{ Skor Soal } & \multirow{2}{*}{ Total Skor } & \multirow{2}{*}{ Skor Maksima } \\
\hline & 1 & 2 & 3 & 4 & 5 & & \\
\hline 1 & 10 & 20 & 7 & 17 & 7 & 61 & 100 \\
\hline 2 & 14 & 14 & 14 & 15 & 5 & 62 & 100 \\
\hline 3 & 13 & 3 & 20 & 15 & 15 & 66 & 100 \\
\hline 4 & 15 & 15 & 18 & 15 & 5 & 68 & 100 \\
\hline 5 & 13 & 13 & 20 & 3 & 20 & 69 & 100 \\
\hline 6 & 14 & 14 & 17 & 17 & 10 & 72 & 100 \\
\hline 7 & 13 & 13 & 20 & 15 & 14 & 75 & 100 \\
\hline 8 & 15 & 15 & 18 & 18 & 12 & 78 & 100 \\
\hline 9 & 13 & 13 & 20 & 18 & 17 & 81 & 100 \\
\hline 10 & 20 & 20 & 20 & 17 & 7 & 84 & 100 \\
\hline
\end{tabular}

Dari data hasil penelitian dengan gaya belajar auditori didapat beberapa skor dari 10 siswa yang merupakan subjek dari gaya belajar auditori yaitu: 61, 62, 66, 68, $69,72,75,78,81,84$.

Tabel 4. Data hasil penelitian dengan gaya belajar kinestetik

\begin{tabular}{|c|c|c|c|c|c|c|c|}
\hline \multirow{2}{*}{ No. } & \multicolumn{5}{|c|}{ Skor Soal } & \multirow{2}{*}{ Total Skor } & \multirow{2}{*}{ Skor Maksima } \\
\hline & 1 & 2 & 3 & 4 & 5 & & \\
\hline 1 & 0 & 10 & 18 & 12 & 17 & 57 & 100 \\
\hline 2 & 0 & 10 & 18 & 12 & 20 & 60 & 100 \\
\hline 3 & 13 & 13 & 18 & 15 & 5 & 64 & 100 \\
\hline 4 & 13 & 13 & 20 & 3 & 20 & 69 & 100 \\
\hline 5 & 10 & 10 & 18 & 15 & 17 & 70 & 100 \\
\hline 6 & 13 & 13 & 13 & 13 & 20 & 72 & 100 \\
\hline
\end{tabular}




\begin{tabular}{cccccccc}
\hline 7 & 15 & 15 & 20 & 15 & 13 & 78 & 100 \\
\hline 8 & 15 & 15 & 20 & 18 & 14 & 82 & 100 \\
\hline 9 & 18 & 18 & 18 & 15 & 20 & 89 & 100 \\
\hline 10 & 20 & 20 & 17 & 20 & 17 & 94 & 100 \\
\hline
\end{tabular}

Dari data hasil penelitian dengan gaya belajar kinestetik didapat beberapa skor dari 10 siswa yang merupakan subjek dari gaya belajar kinestetik yaitu: 57, 60, 64, $69,70,72,78,82,89,94$.

Tabel 5. Nilai rerata data yang diperoleh

\begin{tabular}{|c|c|c|c|c|c|c|}
\hline \multirow{2}{*}{ Gaya Belajar } & \multicolumn{5}{|c|}{ Rerata Skor Soal } & \multirow{2}{*}{ Rerata Total Skor } \\
\hline & 1 & 2 & 3 & 4 & 5 & \\
\hline Visual & 12,3 & 14,6 & 16,3 & 14,6 & 11,4 & 69,2 \\
\hline Auditori & 14 & 14 & 17,4 & 15 & 11,2 & 71,6 \\
\hline Kinestetik & 11,7 & 13,7 & 18 & 13,8 & 16,3 & 73,5 \\
\hline
\end{tabular}

Berdasarkan data pada tabel 5 didapat bahwa rerata total skor untuk gaya belajar kinestetik sebesar 73,5, unggul 1,9 dari gaya belajar auditori yang memiliki skor rata rata sebesar 71,6 dan unggul 4,3 dari gaya belajar visual yang memiliki skor rata rata sebesar 69,2. Sedangkan gaya belajar auditori unggul 2,4 dari gaya belajar visual.

Selanjutnya dibagi kategori kemampuan komunikasi siswa berdasarkan rentang nilai, yaitu rendah, sedang, dan tinggi.

Tabel 6. Hasil penelitian setelah dikategorikan

\begin{tabular}{cccc}
\hline Gaya Belajar & \multicolumn{3}{c}{ Kategori kemampuan } \\
\cline { 2 - 4 } & Rendah & Sedang & Tinggi \\
\hline Visual & 5 siswa & 4 siswa & 1 siswa \\
\hline Auditori & 5 siswa & 5 siswa & 0 siswa \\
\hline Kinestetik & 5 siswa & 3 siswa & 2 siswa \\
\hline
\end{tabular}

Berdasarkan data yang didapat pada tabel 6 diperoleh bahwa pada gaya belajar visual terdapat 5 siswa dengan kategori rendah, 4 siswa dengan kategori sedang, dan 1 siswa dengan kategori tinggi, sedangkan pada gaya belajar auditori terdapat 5 siswa dengan kategori rendah, 5 siswa dengan kategori sedang, dan 0 siswa dengan kategori tinggi, lalu pada gaya belajar kinestetik terdapat 5 siswa dengan kategori rendah, 3 siswa dengan kategori sedang, dan 2 siswa dengan kategori tinggi.

Tabel 7. Hasil rerata data penelitian setelah dikategorikan

\begin{tabular}{cc}
\hline Gaya belajar & Kategori kemampuan \\
\hline Visual & Rendah \\
\hline Auditori & Sedang \\
\hline Kinestetik & Sedang \\
\hline
\end{tabular}

Berdasarkan data yang diperoleh pada tabel 7 didapat bahwa hasil rerata data siswa yang memiliki gaya belajar visual dapat dikategorikan masih dalam kemampuan rendah, sedangkan pada gaya belajar auditori dan kinestetik dapat dikategorikan dalam kemampuan sedang. 
Selanjutnya dilihat bagaimana hasil jawaban siswa dalam memenuhi kemampuan komunikasi matematisnya.

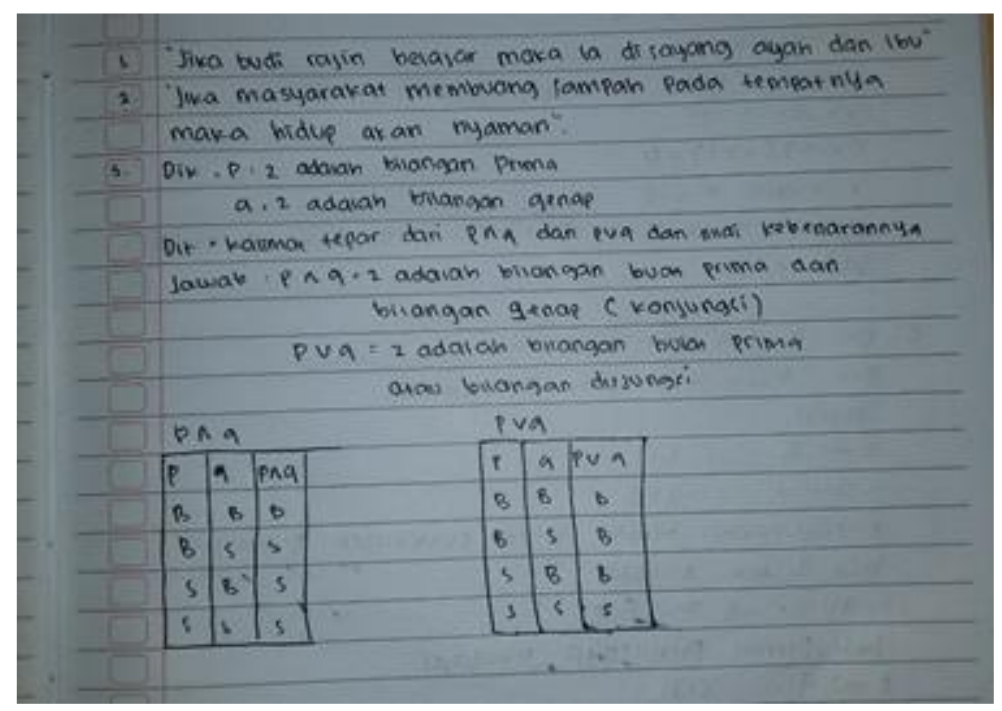

Gambar 1. Salah satu jawaban dari subjek dengan gaya belajar visual

Pada gambar 1 terlihat bahwa jawaban dari subjek dengan gaya belajar visual masih belum baik dalam mengkomunikasikan jawaban secara matematis seperti yang sudah tertera pada indikator.

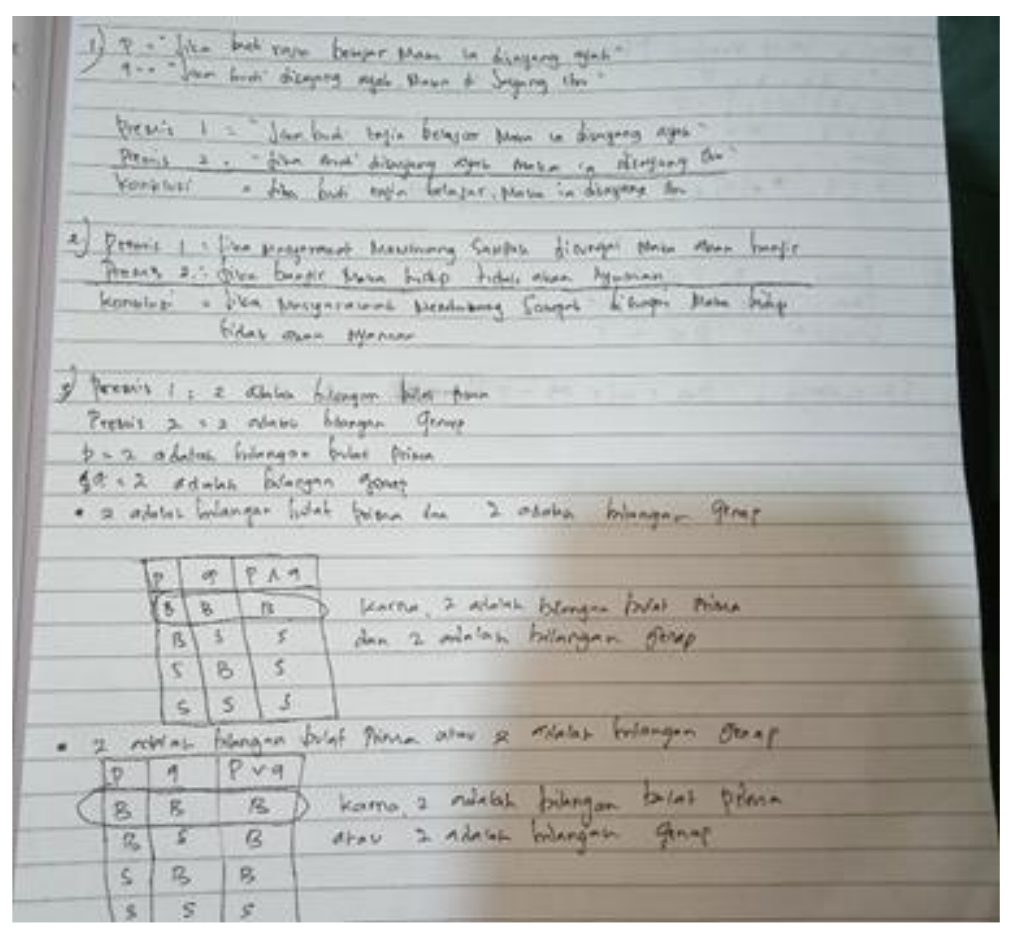

Gambar 2. Salah satu jawaban dari subjek dengan gaya belajar auditori 
Pada gambar 2 terlihat bahwa jawaban dari subjek dengan gaya belajar auditori sudah cukup baik dalam mengkomunikasikan jawaban secara matematis seperti yang sudah tertera pada indikator walaupun masih ada indikator yang belum tercapai.

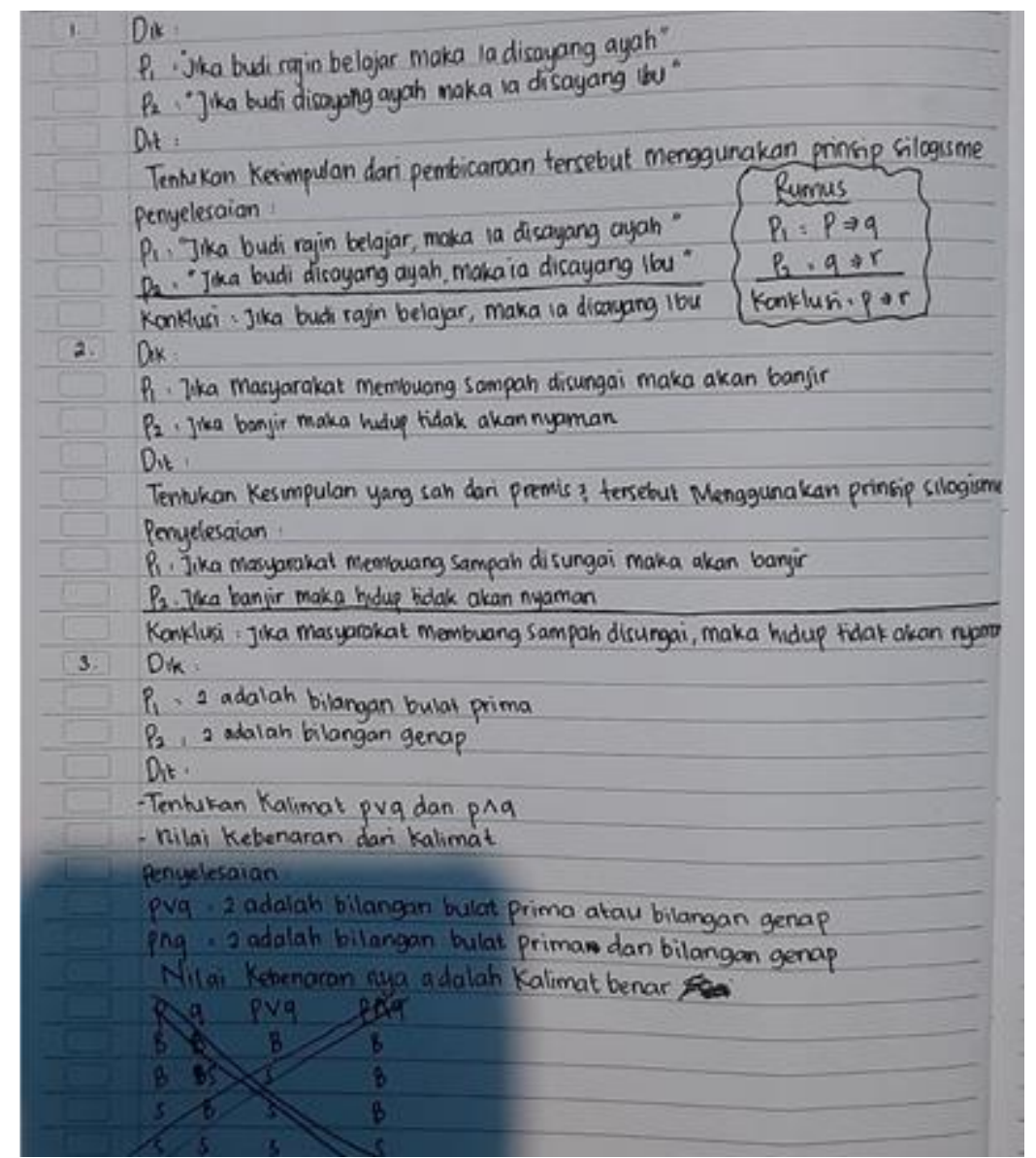

Gambar 3. Salah satu jawaban dari subjek dengan gaya belajar kinestetik

Pada gambar 3 terlihat bahwa jawaban dari subjek dengan gaya belajar kinestetik sudah baik dalam mengkomunikasikan jawaban secara matematis seperti yang sudah tertera pada indikator.

\section{SIMPULAN DAN SARAN}

Berdasarkan hasil penelitian yang didapat mengenai kemampuan komunikasi matematis siswa yang ditinjau dari gaya belajar, diperoleh bahwa (1) kemampuan komunikasi matematis dengan gaya belajar visual berada pada kategori kemampuan rendah, (2) kemampuan komunikasi matematis dengan gaya belajar auditori berada pada kategori kemampuan sedang, dan (3) kemampuan komunikasi matematis dengan gaya belajar kinestetik berada pada kategori kemampuan sedang. Namun jika ditinjau dari hasil tabel 6 tentang hasil penelitian yang telah dikategorikan dapat dikatakan bahwa gaya belajar kinestetik lebih baik daripada gaya belajar visual maupun auditori, karena terdapat 2 siswa dengan gaya belajar kinestetik berkategori tinggi, dan 3 siswa pada kategori sedang. Selanjutnya pada tabel 7 tentang hasil 
rerata data setelah dikategorikan mendapatkan hasil yang lebih umum yaitu gaya belajar visual berada pada kategori rendah, sedangkan gaya belajar auditori dan kinestetik berada pada kategori sedang. Berdasarkan data yang didapat pada tabel 4 didapat bahwa rerata total skor yang didapat gaya belajar kinestetik unggul 1,9 dari gaya belajar auditori dan unggul 4,3 dari gaya belajar visual.

Disarankan kepada guru ataupun tenaga pendidik lainnya agar lebih memperhatikan gaya belajar siswa, karena dengan memperhatikan gaya belajar siswa dapat lebih memperbaiki dan meningkatkan kemampuan komunikasi matematisnya.

\section{DAFTAR PUSTAKA}

De Porter, B dan M. Hernacki. 2015. Quantum Learning. Bandung: Kaifa.

Greenes, C. and Schulman, L. 1996. Communication Processes in Mathematical Explorations and Investigations. In P. C. Elliot and M. J. Kenney (Eds). 1996 Yearbook. Communication in Mathematics. K-12 and Be. Vond. USA : NCTM. Lanani, K. 2013. Belajar Berkomunikasi dan Komunikasi untuk Belajar dalam Pembelajaran Matematika. Infinity Journal, Vol. 2(1) : 13-25.

Mousa, N. M. 2014. The Importance of Learning Styles in Education. International Journal of Education. Vol. 1. 19-27.

Nari, N. 2015. Kemampuan Komunikasi dan Disposisi Matematis Mahasiswa pada Mata Kuliah Geometri. Jurnal Ta'dib, Vol. 18(2) : 150-162.

Nasution, S. 2016. Upaya Meningkatkan Aktivitas Belajar dan Kemampuan Komunikasi Matematika Siswa Pada Materi Bangun Ruang Melalui Strategi Pembelajaran Kontekstual di Kelas VIII SMP Muhammadiyah 02 Kecamatan Medan Perjuangan Tahun Pelajaran 2014/2015. AXIOM : Jurnal Pendidikan \& Matematika, Vol. 5(1) : 30-40.

Prayitno, S., Suwarsono, St., dan Siswono, T.Y.E. 2013. Komunikasi Matematis Siswa SMP dalam Menyelesaikan Soal Matematika Berjenjang Ditinjau dari Perbedaan Gender. Makalah Pada Prosiding Seminar Nasional Matematika dan Pendidikan Matematika Jurusan Pendidikan Matematika FMIPA Universitas Negeri Yogyakarta. Yogyakarta, 9 November 2013. ISBN : 978979-16353-9-4.

Prinansa, D. J. 2017. Pengembangan Strategi \& Model Pembelajaran. Bandung: CV Pustaka Setia.

Putri, R. I. 2011. Upaya Meningkatkan Kemampuan Komunikasi Matematis Siswa dalam Pembelajaran Matematika Melalui Pendekatan Reciprocal Teaching dengan Model Pembelajaran Kooperatif di Kelas VIII-D SMP Negeri 4 Magelang. Skripsi tidak diterbitkan. Yogyakarta: FMIPA Universitas Negeri Yogyakarta.

Romli, M. 2010. Strategi Membangun Metakognisi Siswa SMA dalam Pemecahan Masalah Matematika. AKSIOMA : Jurnal Matematika dan Pendidikan Matematika, Vol. 1(2) : 1-17.

Supriadi, N. dan Damayanti, R. 2016. Analisis Kemampuan Komunikasi Matematis Siswa Lamban Belajar dalam Menyelesaikan Soal Bangun Datar. Al-Jabar: Jurnal Pendidikan Matematika, Vol. 7(1) : 1-9.

Syahri, A.A. 2017. Pengaruh Penerapan Pendekatan Realistik Setting Kooperatif Terhadap Kemampuan Komunikasi Matematika Siswa Kelas VIII. MaPan: Jurnal Matematika \& Pembelajaran, Vol. 5(2) : 216-235. 
Tandililing, E. 2011. Peningkatan Pemahaman dan Komunikasi Matematis serta Kemandirian Belajar Siswa SMA Melalui Strategi PQ4R dan Bacaan Refutation Text. Disertasi tidak diterbitkan. Bandung: Universitas Pendidikan Indonesia.

Taufiq. 2014. Meningkatkan Kemampuan Komunikasi dan Pemecahan Masalah serta Disposisi Matematik Siswa SMP Melalui Pendekatan Kontekstual dan Strategi Think Talk Write. Tesis tidak diterbitkan. Bandung: Universitas Pendidikan Indonesia.

Widjajanti, D. B. 2013. The Communication Skills and Mathematical Connections of Prospective Mathematics Teacher: A Case Study on Mathematics Education Students, Yogyakarta State University, Indonesia. Jurnal Teknologi (Social Science). 63(2) : 39-43.

Wulandari, I.A.D., Suarsana, I M., dan Pujawan, I G.N. 2018. Model Pembelajaran Kooperatif Talking Stick, Mind Mapping, dan Kemampuan Komunikasi Matematis. MaPan: Jurnal Matematika \& Pembelajaran, Vol. 6(1) : 82-93. 